\title{
st \\ A propósito da condenação de Feyerabend em Roma por causa de suas ideias sobre o conflito entre a Igreja e Galileu
} Paulo dos Santos Terra

\author{
Há muitas maneiras de silenciar as pessoas, \\ além de proibi-las de falar- \\ e todas elas estão sendo usadas hoje.
} (Feyerabend, 2007, cap. 13, p. 183).

Já havia nos meios acadêmicos um alerta claro a propósito das ideias do filósofo Paul Karl Feyerabend (1924-1994), visto que nas páginas da revista Nature ele foi qualificado de "o mais perigoso inimigo da ciência" (Theocharis \& Psimopoulos, 1987, p. 596).

Parece que esse sentimento de perigo com relação ao pensamento de Feyerabend aumentou, por conta de um episódio que envolveu, em janeiro de 2008, o papa Bento xvI, que foi impedido, por um grupo de professores apoiados por estudantes, de proferir a aula pública inaugural do ano letivo da Universidade La Sapienza, em Roma. Resumidamente, a alegação desse grupo foi a de que o papa, quando era cardeal, proferiu uma palestra, no ano de 1990, em que afirmou, apoiando-se em uma citação de Feyerabend, que, por ocasião dos famosos processos a que Galileu Galilei foi submetido perante o Santo Ofício da Inquisição, o tratamento que ele recebeu foi razoável e justo (cf. Ratzinger, 199o). Tal fato, somado ao de que o último cargo ocupado pelo cardeal Ratzinger antes de sua eleição para o trono papal foi o de prefeito da Congregação para a Doutrina da Fé, sucessora do Santo Ofício, pareceu bastante para que se postulasse a inclusão de Bento xvi no rol dos inimigos da ciência e da vida acadêmica. Com efeito, a aula do papa Bento xvi foi substituída por outra que tratou da pena de morte e o texto da conferência papal (cf. Bento xvI, 2008) foi apenas divulgado em meio eletrônico.

Esses acontecimentos de La Sapienza ligam Bento xvi a Feyerabend porque o referido parecer de que o processo inquisitorial de Galileu foi razoável e justo foi baseado na epígrafe do capítulo 13 de Contra o método (cf. Feyerabend, 2007, p. 181).

Assim, se Feyerabend já era julgado por alguns como inimigo da ciência, muito mais agora que tem suas ideias usadas no discurso de alguém que é tido comumente 
nos meios acadêmicos como obscurantista, e que o cita textualmente. Mas o que poderiam dizer os admiradores de Feyerabend?

Há que considerar na análise desse assunto o seguinte. Parece estar em pleno desenvolvimento uma luta cultural entre dois fortes grupos, na qual está envolvida a figura de Galileu Galilei, que se encontra colocada como um objeto de disputa. De um lado, posicionam-se muitos cientistas profissionais e outros acadêmicos que sustentam que Galileu personifica a liberdade da investigação científica e a busca pela verdade e que a Igreja Católica é exatamente o oposto disso, argumento que ilustram comumente com a narrativa dos célebres acontecimentos que ocorreram no século xviI. De outra parte, encontram-se membros da cúpula da Igreja Católica e simpatizantes, que fazem análise diferente do famoso caso Galileu e que buscam, apoiados na obra do polêmico cientista e filósofo, e em outra interpretação dos julgamentos de Galileu, erigir um sistema de ideias que parte do princípio de que ciência e fé nunca se opuseram e que não devem atuar separadamente, sobretudo nos dias de hoje.

É nessa disputa cultural que se vê envolvida subitamente a filosofia anarquista de Feyerabend. Tal fato não é de surpreender. Com efeito, encontra-se na obra do filósofo farto material para discutir o caso Galileu sob diversos ângulos. Contudo, há algo mais, que será considerado aqui com alguma ênfase. A filosofia anarquista epistemológica fornece elementos também para a análise do embate cultural supramencionado, assim como para apontar o próprio fato como um acontecimento importante para a compreensão da cultura contemporânea.

Assim, como primeiro procedimento de trabalho, há que analisar detidamente o episódio de La Sapienza, sobretudo quanto à gênese do movimento discente de oposição ao papa.

\section{Sessenta e sete professores gontra o papa, por causa de Feyerabend}

Qual a origem do movimento de oposição ao papa Bento xvi deflagrado pelos professores da setissecular universidade romana La Sapienza? Esse movimento de contraposição iniciou-se quando o professor aposentado de física, Marcello Cini, após tomar conhecimento pela imprensa de que o papa havia sido convidado para proferir a aula inaugural na universidade La Sapienza, escreveu ao reitor uma carta aberta de protesto (cf. Cini, 2007). Cini afirma que o convite ao papa para abrir o ano acadêmico da universidade representa retrocesso de trezentos anos, visto que "desde a condenação de Galileu por parte do Santo Ofício, há separação entre as esferas de competência da Academia e da Igreja" (Cini, 2007). Ademais, Cini examinou trechos da aula inaugural proferida pelo papa em Regensburg (Alemanha), em 12 de setembro de 2006 (cf. Bento xvI, 2006b), 
na qual ele julga encontrar indícios de que a linha política do atual papa funda-se na tese de que a separação entre as respectivas esferas de competência da fé e da razão "não valem mais" (Cini, 2007). Por considerar que o papa afirma que a razão deve submeter-se à fé, Cini conclui sua argumentação dizendo que o convite ao "ex-chefe do Santo Ofício [...] é imprevidente e lesivo à imagem de La Sapienza perante o mundo" (Cini, 2007).

Como, não obstante a manifestação enfática do professor Cini, a aula programada foi confirmada, 67 professores, físicos em sua maioria, redigiram carta de protesto dirigida ao reitor:

Magnífico Reitor, com estas poucas linhas desejamos fazê-lo saber que apoiamos totalmente a crítica que nosso colega Marcello Cini lhe dirigiu pela imprensa, relativamente à desconcertante iniciativa de convidar o papa Bento xvi para a abertura do ano acadêmico de La Sapienza. Nada há que acrescentar aos argumentos de Cini, com exceção de um pormenor. Em 15 de março de 1990, quando ainda era cardeal, em um discurso na cidade de Parma, ' Joseph Ratzinger retomou uma afirmação de Feyerabend: "Na época de Galileu, a Igreja se ateve à razão mais do que o próprio Galileu. O processo contra Galileu foi razoável e justo". São palavras que, como cientistas fiéis à razão e como professores que dedicam sua vida ao progresso e à difusão do conhecimento, nos ofendem e nos humilham. Em nome da laicidade da ciência e da cultura e no respeito deste nosso Ateneu, aberto a professores e estudantes de todo credo e de toda ideologia, esperamos que o incoerente evento ainda possa ser anulado (Lettera, 2007).

Como se vê, os signatários do manifesto de La Sapienza, que se definiram "cientistas fiéis à razão", declaram que se sentiram ofendidos e humilhados pelas palavras de Feyerabend usadas pelo cardeal Ratzinger, citação que foi decisiva para a declaração de que o papa Bento xvı fosse declarado persona non grata àquela instituição acadêmica. Que concluir disso senão que a condenação do papa é extensiva também ao filósofo, que deve, pois, ser considerado, segundo o parecer dos insignes acadêmicos, como inimigo da razão, do progresso, da difusão do conhecimento, da laicidade da ciência e da cultura e, por tudo isso, da vida acadêmica?

1 Cabe mencionar que os redatores do documento equivocaram-se quanto ao local da palestra mencionada. Ela não ocorreu em Parma, mas em Roma; e em La Sapienza! A informação estava errada no verbete "Joseph Ratzinger", na Wikipedia em italiano, de onde parece que foi retirada (cf. Zenit, 2008). 


\section{Feyerabend e suas ambiguidades sobre Galileu}

No capítulo 13 de Contra o método, que trata do julgamento de Galileu, e que foi adicionado na segunda edição, encontram-se as seguintes passagens: "Galileu teve um tratamento bastante suave [por parte dos inquisidores], apesar de suas mentiras e tentativas de trapacear" (Feyerabend, 2007, p. 183); "a ideia do movimento da Terra [tal como defendida por Galileu] era [na época] tão absurda como o foram as ideias de Velikovsky quando comparadas com os fatos, teorias e padrões dos anos 1950" (p. 186). ${ }^{2}$

Esse pequeno florilégio já contém material bastante para infindas e ácidas discussões, mas o que importa aqui é o que parece ter chamado a atenção do cardeal e hoje papa, fazendo-o mencionar o filósofo austríaco, e que, ademais, parece estar orientando uma estratégia política da Igreja iniciada pelo papa João Paulo II, antecessor de Bento xvi. Trata-se do problema das implicações ético-sociais que envolveram as discussões no século xviı e que sustentaram as decisões tomadas pela Igreja por ocasião da célebre polêmica cosmológico-teológica.

\section{Feyerabend e as implicações Ético-sociais do caso Galileu}

No capítulo 16 da primeira versão de Contra o método (Feyerabend, 1989, p. 296 ss.), Feyerabend discute, ainda que incompletamente, quais são os comportamentos passíveis de adoção por alguém do século xvir que viesse a tomar conhecimento da teoria de Copérnico e quisesse fazer algo em relação a ela. Feyerabend analisa três esquemas de ação, dois deles adotados por Galileu e o outro pelos seus inquisidores.

Galileu ter-se-ia motivado pelo potencial revolucionário contido na teoria copernicana e não mediu esforços em recorrer aos recursos possíveis e usar seu prestígio pessoal para transformar a ideia heliocêntrica num instrumento acerado que pudesse destruir o sistema aristotélico-ptolomaico e o sistema cultural armado em torno dele. Adicionalmente, Galileu desenvolveu argumentos que punham ênfase na superioridade do modelo copernicano em relação ao ptolomaico e criavam a ideia irresistível de que se estava diante de um salto epistemológico extraordinário em relação ao qual não havia como, nem por que se opor.

O terceiro modo de ação possível pautava-se no cuidado de impedir que os dois cursos de ação acima descritos, o de revolucionário cultural e o de promotor de uma revolução epistemológica, fossem levados adiante, visto que Galileu desconsiderava o

2 Custa a muitos crer que quem disse isso de Galileu tem-no, por paradoxal que pareça, como um herói, pois Contra o método é uma apologia de Galileu, onde ele é apresentado como modelo a ser seguido. 
tumulto que seria causado pela apresentação da teoria copernicana, rica em polêmicas teológicas, sem que a teoria estivesse solidamente demonstrada, isto é, sem que tivesse efetivamente alguma prova que atestasse a sua validade. Poder-se-ia defender as novas ideias tão-somente por suas qualidades instrumentais, pelo que possibilitava em termos de cálculos astronômicos, e nada além disso, até que as provas necessárias de validade fossem encontradas. Esse comportamento cauteloso visava a considerar antes e acima de tudo a paz social e, assim, subordinava qualquer outro interesse ou valor que se pudesse ligar à teoria copernicana ao princípio de não perturbar injustificadamente a ordem pública. Teria sido esse o pensamento do cardeal Roberto Bellarmino e que norteou sua atuação no dito primeiro processo de Galileu.

Nesse interessante enfoque da complexa problemática que envolveu os processos inquisitoriais de Galileu, Feyerabend parece vacilar em alguns aspectos, como o provam os diferentes tratamentos dados ao assunto, nas diversas edições de Contra $o$ método; ao manter a ideia de que Galileu perdeu a disputa, quer por ter falhado na condução das estratégias referentes à defesa do conteúdo científico da teoria copernicana, quer, sobretudo, por desconsiderar as implicações ético-sociais negativas e por recusar-se a adotar as soluções técnicas propostas pelos inquisidores e acordadas com eles, percebe-se que Feyerabend tem dificuldade de avaliar a atuação do cardeal Roberto Bellarmino.

Feyerabend hesita, pois, curiosa e inexplicavelmente, em admitir que o cardeal Roberto Bellarmino foi um hábil anarquista epistemológico. Embora diga na primeira edição de Contra o método que ele estava "longe de ser um anarquista" (Feyerabend, 1989, p. 296), logo em seguida a essa afirmação, transcreve trechos de uma biografia do cardeal, santo e doutor da Igreja, que denotam evidente simpatia pela motivação da hábil estratégia que o purpurado desenvolveu para opor-se à “"precipitação impetuosa de Galileu'" (p. 296). Compreende-se muito mais ricamente a polêmica de 1616, sob a óptica desenvolvida por Feyerabend, se a vemos como uma batalha entre dois gigantes anarquistas epistemológicos, que, guiados por princípios diferentes, buscam anular um a estratégia do outro. Guinado à condição de anarquista que pauta suas ações pelo critério da paz social, Bellarmino torna-se um herói anarquista epistemológico modelar, cujas estratégias podem ser adaptadas para várias situações, como aliás parece estar ocorrendo nos dias de hoje, de parte da alta hierarquia da Igreja, como se procurará demonstrar a seguir. 


\section{Feyerabend E uma técnica de faZer amigos e MANTER A PAZ}

Eis o último parágrafo do capítulo 13 de Contra o método, que trata do julgamento de Galileu, conforme a terceira edição, que resume a posição do filósofo sobre o fim do caso Galileu e sobre o desdobramento dele hoje em dia:

A avaliação dos peritos da Igreja estava cientificamente correta e tinha a intenção social certa, a saber, proteger as pessoas das maquinações dos especialistas [isto é, de Galileu]. Desejava proteger as pessoas de serem corrompidas por uma ideologia estreita que podia funcionar em domínios estritos, mas era incapaz de sustentar uma vida harmoniosa. Uma revisão [no final do século XX] da avaliação [dos peritos eclesiais seiscentistas] poderia conquistar à Igreja alguns amigos entre os cientistas, mas prejudicaria severamente sua função como preservadora de importantes valores humanos e sobre-humanos (Feyerabend, 2007, p. 192).

Essa posição foi sustentada por Feyerabend, considerando a data do prefácio da terceira edição de Contra o método, em julho de 1992 (Feyerabend, 2007, p. 18). Ora, nessa época já há onze anos desenvolviam-se os trabalhos da comissão pontifícia instituída pelo papa João Paulo in para reexaminar o caso Galileu; e estava próximo seu encerramento formal, 31 de outubro de 1992. As palavras de Feyerabend tinham certamente como destinatário o próprio papa, cujas intenções relativas ao caso Galileu eram demasiado cristalinas para que ele não as percebesse.

Na nota associada ao parágrafo acima transcrito, Feyerabend elogia o cardeal Josef Ratzinger, pelo seu discurso de 15 de março de 1990 (que ele também aponta ter sido pronunciado em Parma e não em Roma), e diz que o purpurado "sustenta posição similar àquela uma vez sustentada por Bellarmino [no caso Galileu] e [assim] formulou o problema [das relações entre a ciência e a religião] de forma que faria a revisão do julgamento [de Galileu] anacrônica e sem sentido" (Feyerabend, 2007, p. 192).

Ora, Feyerabend não se deu conta de que as lições do cardeal Bellarmino, relativas ao trato das questões que envolvem ciência e religião, não foram assimiladas apenas pelo cardeal Ratzinger, mas também as foram pelo papa João Paulo II, não havendo senão divergência aparente entre eles, visto que um e outro estabeleceram como baliza de pensamento as implicações ético-sociais que essas complexas, multifárias e importantes questões envolvem. O papa João Paulo II já a aplicara, mutatis mutandis, à estratégia do cardeal Bellarmino, quando deu início ao reexame do caso Galileu, em 1979. É possível que exatamente por causa desse seguimento das ideias de Bellarmino, mantém-se a situação de conflito cultural entre a Igreja e certos setores culturais e ideologias, em que o episódio La Sapienza é um caso típico. 
A propósito da condenação de Feyerabend em Roma...

\section{João Paulo it, a revisão do Gaso Galileu e a nova imagem de Galileu}

Passado um ano de sua eleição para o trono pontifício, João Paulo II anunciou a intenção de reexaminar o caso Galileu e nomeou para esse fim uma comissão que iniciou os trabalhos em 1981, encerrando-os em 1992, concluindo que Galileu foi vítima de erro de julgamento por parte dos inquisidores.

Em 10 de novembro de 1979, João Paulo ir proferiu discurso na Pontifícia Academia de Ciências em que mencionou Galileu e disse que ele "muito teve que sofrer [...] da parte de homens e organismos da Igreja” (João Paulo II, 1979, §6). Prossegue o papa acrescentando que já na constituição apostólica Gaudium et spes, que compõe o conjunto de documentos do Concílio Ecumênico Vaticano iı, de 1965, e trata das relações da Igreja como o mundo, os padres conciliares referiram-se a Galileu e apontaram que alguns cristãos incorriam no erro de não reconhecer a autonomia da ciência e que isso gerava tensões e conflitos que levaram muitos a crer erroneamente que fé e ciência são irreconciliáveis (cf. João Paulo II, 1979, § 6). No mesmo documento, afirma João Paulo II, destacou-se o desejo de que se reconhecessem os erros cometidos, desfizessem-se as desconfianças e se instaurasse espírito de concórdia, com o que seriam estabelecidas relações frutuosas entre a ciência e a fé.

Ao tratar das diretrizes necessárias para a criação desse ambiente de pacífica cooperação, afirmou o papa João Paulo II que a concórdia entre fé e ciência tem como fulcro aquilo que o próprio Galileu estabeleceu na carta ao Padre Benedetto Castelli, datada de 21 de dezembro de 1613, em que afirma o princípio da não contradição entre as duas verdades, a da fé e a da ciência (cf. João Paulo II, 1979, § 7). João Paulo II continua afirmando que Galileu introduziu ainda um outro princípio, este de natureza exegética, estabelecido na famosa carta à Grã-duquesa mãe Cristina de Lorena, escrita em 1615, em que ele postula que a interpretação dos textos sagrados deve buscar o que há além do sentido literal e levar em conta a intenção do hagiógrafo, as peculiaridades de sua época e as características do gênero literário usado por ele. Galileu, ressalta João Paulo II, valeu-se de regras perenes de interpretação da Sagrada Escritura que estão em conformidade com o que recomenda o magistério eclesiástico, como se lê, por exemplo, na encíclica Divino afflante spiritu, de Pio xiı (cf. João Paulo II, 1979, § 7). Assim, para o papa João Paulo II, Galileu estabeleceu o protocolo de como se devem dar as relações entre fé e ciência. Sigam-se as regras galileanas, recomenda o papa; se isso tivesse sido feito, desde o início do século xvıI, nenhum conflito teria ocorrido, visto que tais regras são atemporais.

João Paulo II expressou seu desejo de que se reexaminasse o caso Galileu e assim se chegasse ao "reconhecimento leal dos erros de qualquer lado que tenham vindo" (João Paulo II, 1979, § 6). Para a realização dessa tarefa, o papa João Paulo II nomeou, 
em 13 de outubro de 1981 (cf. João Paulo II, 1981), uma comissão pontifícia, cuja conclusão foi que "os juízes de Galileu" erraram em crer que a revolução copernicana afetava a fé católica (apud Accatoli, 1997, p. 131).

Ouvido o relatório final, João Paulo II analisou as ideias de Galileu pertinentes ao âmbito teológico. Retomou os pontos já tratados em 1979, mas deu ênfase à carta de Galileu à Grã-duquesa Cristina de Lorena, de 1615, que ele qualificou de "um pequeno tratado de hermenêutica bíblica" (João Paulo II, 1992, §5). Afirmou ainda que o caso Galileu é "uma espécie de mito", cunhado pelos iluministas, que é usado para atacar a Igreja Católica e apontar falsamente a existência de "oposição estrutural entre ciência e fé” (João Paulo II, 1992, § 10). Pode-se dizer que João Paulo II lançou nesse momento uma campanha de combate ao que denominou mito iluminista de Galileu, que se trata de um projeto político-cultural que aparenta visar a inserir a doutrina cristã católica na discussão dos problemas capitais da ciência e da tecnologia.

\section{JoÃo Paulo it e as técnicas inspiradas por Bellarmino para o AGolhimento a Galileu}

Tem certamente razão Feyerabend em dizer que promover no âmbito da Igreja a revisão, ou algo que se assemelhe a isso, do caso Galileu e concluir que, de algum modo, o que se fez foi incorreto não pode ter alguma outra intenção que a de "conquistar à Igreja alguns amigos entre os cientistas" (Feyerabend, 2007, p. 192). É difícil dizer que não foi essa a intenção de João Paulo II, que pareceu não ter medido esforços em derrubar o que possa ser usado para criar animosidade entre o meio acadêmico e a Igreja (cf. Artigas, 2006; Guimarães, 2008).

Pode-se conjeturar que João Paulo II usou a mesma tática anarquista epistemológica que Feyerabend diz ter provavelmente orientado a conduta do cardeal Bellarmino por ocasião de sua participação no dito primeiro processo de Galileu (cf. Feyerabend, 1989, p. 296). Ambos preocuparam-se antes de qualquer coisa com a paz social. Bellarmino procurou impedir que uma teoria científica possível, mas não provada, o heliocentrismo defendido por Galileu, fosse apresentada como verdadeira e causasse polêmica teológica desnecessária; buscou evitar a todo custo, e nisso foi bem sucedido, que os interesses pessoais de Galileu (apresentar como provada uma teoria que não se sustentava sobre provas válidas) prevalecessem sobre regras metodológicas (não apresentar teorias que têm apenas valor instrumental como descrições reais do mundo) e sobre conveniências ético-sociais (não abalar a crença das pessoas com meras conjeturas). Conseguido o intento de frustrar as ambições de Galileu, a paz social, na visão 
de Bellarmino, estabelecer-se-ia automaticamente, quer no mundo acadêmico, onde a substituição do modelo ptolomaico pelo copernicano não teria de ser imposta pela força da retórica e da articulação política, quer no mundo teológico, onde não se perderia tempo com discussões inúteis.

João Paulo II interessou-se também em estabelecer clima social pacífico na cultura contemporânea, nem que para isso necessitasse sacrificar a verdade histórica. Não lhe era importante buscar medir o grau de culpa que Galileu teve nos acontecimentos famosos. Bastava-lhe que a Igreja reconhecesse, com longanimidade, que membros seus erraram e que, por isso, e tão somente por isso, "Galileu teve de sofrer muito". Importou tão-somente a João Paulo Iı, ao que parece, conquistar a boa vontade e a atenção da comunidade científica e tornar injustificável a indisposição para o debate e para a colaboração. Nesse sentido, João Paulo II esforçou-se no trabalho pela restauração de uma cultura que se assente no binômio fé e razão. O assunto foi tema da carta encíclica Fides et ratio, que expressa claramente essa posição já nas primeiras palavras: "A fé e a razão constituem como que as duas asas pelas quais o espírito humano se eleva para a contemplação da verdade" (João Paulo II, 1998). Nessa encíclica, Galileu é mencionado em uma nota de rodapé (cf. João Paulo II, 1998, §34, n. 29).

A admiração e estima de João Paulo II por Galileu não se limitou às várias expressões verbais; os sentimentos do papa pelo filósofo foram até materializados em metal. Tome-se a medalha comemorativa do quarto centenário da Pontifícia Academia de Ciências, que se festejou em 2003. Vê-se no anverso da medalha, circundado por texto em latim, que se refere ao motivo da comemoração e relaciona a atual Academia à Academia dos Linces, o papa João Paulo ı e Galileu, que tem atrás dele a representação de seu sistema heliocêntrico, com Júpiter e as suas quatro estrelas medicéias e Saturno como ele o julgava ver, com as duas grandes luas em torno dele. No verso da medalha, lê-se em latim "A luz da fé e a da razão, tanto uma quanto outra, originam-se de Deus"; complementarmente, vê-se a representação disso, por meio de uma figura masculina de longa barba e auréola triangular, que porta uma tocha, na qual acendem as suas tochas duas figuras femininas jovens que parecem gêmeas.

No sítio eletrônico da Pontifícia Academia de Ciências também se encontra a figura de Galileu. Vemo-lo representado em idade madura, circundado por equipamentos científicos, que incluem o seu telescópio e o seu compasso geométrico militar; um globo celeste, estrategicamente localizado, parece-lhe aureolar a cabeça. Assim é, pois, o Galileu de João Paulo Iı, reconciliado com a Igreja e figura cujas ideias são indispensáveis para a condução das complexas questões que envolvem a ciência e a fé católica. Falta-lhe, parece, algo ainda e o sucessor de João Paulo iı prossegue o trabalho de construção. 


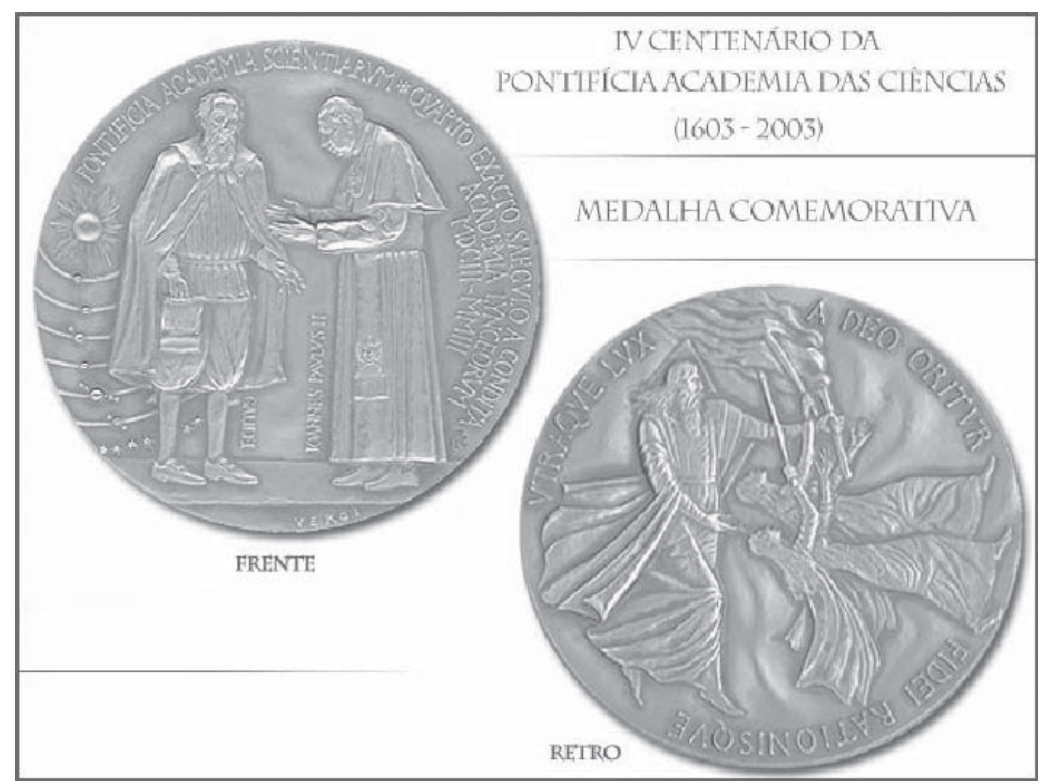

Figura 1. Ilustração da medalha cunhada em 2003 para a comemoração do quarto centenário da Academia Pontifícia de Ciências do Vaticano, cujas raízes, segundo a página oficial da Academia, estariam na Academia dos Linces (Accademia dei Lincei), fundada em Roma em 1603 por Federico Cesi. AAcademia, extinta ainda no século XVII, foi restabelecida em 1847 pelo papa Pio IX com o nome de Academia Pontifícia dos Novos Linces. Em 1936, a Academia foi reformada pelo papa Pio XI e adquiriu a atual denominação, Pontificia Academia Scientiarum, cuja sede está situada nos jardins do Vaticano. Galileu Galilei foi admitido em 1611 na Academia dos Linces, que tinha como lema: minima cura si maxima vis (cuida das coisas pequenas se queres obter as grandes). A imagem da medalha comemorativa achava-se visível na página.

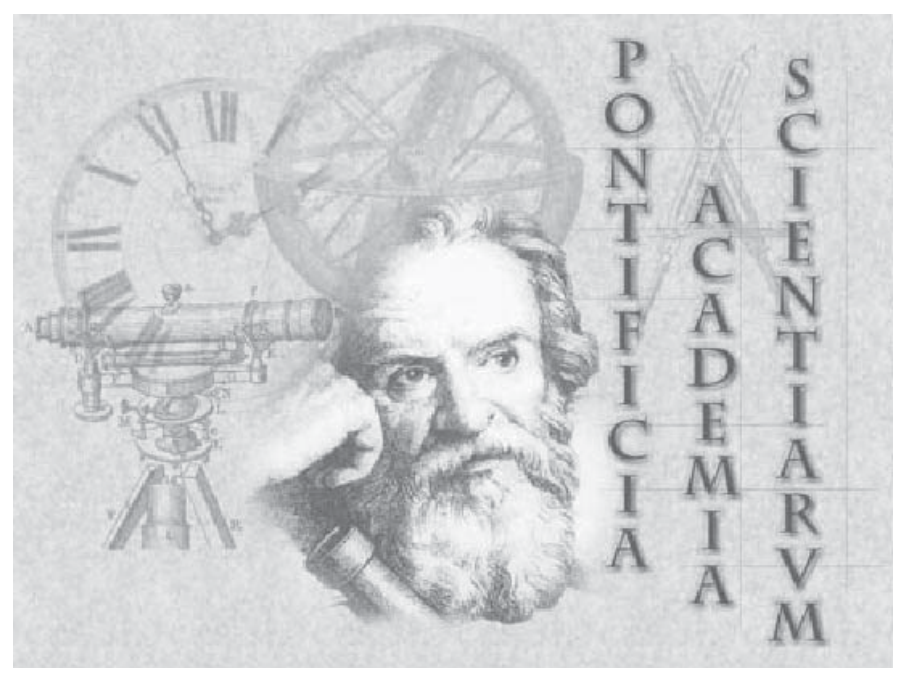

Figura 2. Ilustração que se encontra na abertura da página eletrônica da Pontifícia Academia de Ciências. (Fonte:www.vatican.va/roman_curia/pontifical_academies/acdscien/index_po.htm) 
A propósito da condenação de Feyerabend em Roma...

\section{Bento xvi e a Ampliação da imagem Regongiliada de Galileu}

Também o papa Bento xvi, sucessor imediato de João Paulo II, vem, ao que parece, dando continuidade ao trabalho de apresentar Galileu como cientista modelar. Fica mais fácil ver como isso se dá a partir de uma crítica adicional que o professor Marcello Cini, desencadeador do movimento de oposição à visita do papa a La Sapienza, fez a Bento XVI, na mesma carta de protesto dirigida ao reitor:

Não podendo mais [Ratzinger/Bento xvI] usar a ameaça e a punição física, inspirou-se ele em Ulisses. Passou a usar a imagem da deusa razão dos iluministas como um cavalo de Tróia para entrar na cidadela da consciência científica e aprisioná-la. Não exagero. Que outra coisa é, para dar um exemplo, o apoio explícito dado pelo papa à assim denominada teoria do design inteligente senão a tentativa [...] de recolocar a ciência sob a pseudo-racionalidade dos dogmas da religião? E como deverão reagir os nossos colegas biólogos e seus alunos frente a um ataque mais ou menos indireto à teoria darwiniana da evolução biológica, que está na base, em todo o mundo, da moderna biologia evolutiva? (Cini, 2007).

A crítica é infundada. Bento xvi afirmou claramente que considera que "é um absurdo" crer que há oposição entre a ideia de criação e a de evolução (Bento xvI, 2007). Mais preocupado com seu papel de panfletista e agitador, Cini buscou pintar a imagem de Bento xvi com tons desagradáveis e com isso convocar para a luta anti-papal também os "colegas biólogos e seus alunos", ao imputar ao pontífice uma simpatia declarada por uma teoria abominada nos meios acadêmicos. Trata-se, para dizer o mínimo, de pura retórica maledicente. É simples perceber que um teísta cristão (que será o papa senão isso?) entenderá a evolução biológica e universal apenas à luz da Quinta Via de Santo Tomás de Aquino, sendo-lhe, pois, repulsiva a ideia de evolução conduzida exclusivamente por força do acaso e perfeitamente aceitável a ideia de evolução dirigida, de algum modo, pela providência divina.

$O$ fato é que Bento xvi trabalha com a ideia de mundo planejado matematicamente por Deus, que Galileu desenvolveu nas conhecidas páginas d'O ensaiador. Isso se depreende de algumas breves menções do papa ao célebre cientista e filósofo (Bento xVI, 2006a e 2006c). Se o papa João Paulo II apresentou Galileu como guia em questões para a condução dos assuntos pertinentes à fé e à razão, Bento xvi começa a apresentar Galileu, para os mesmos fins, como orientador em matéria de filosofia natural. 


\section{DisGussão FINAL}

A polêmica da aula magna do papa Bento xvı na universidade romana La Sapienza é mais um episódio de um antigo conflito cultural que, ao que tudo indica, tende a ganhar maiores proporções nos tempos presentes. Em um dos polos desse embate intelectual situa-se a complexa figura de Galileu Galilei. Usado habitualmente pelos adversários da Igreja para atacá-la, Galileu é, nos últimos anos, peça da sua estratégia de contra-argumentação, na qual as ideias dele constituem parte importante dos elementos de sustentação de uma visão arquitetada, pelos dois últimos papas, para acomodar os progressos teóricos científicos com a filosofia cristã. Com essa articulação, a Igreja parece claramente tomar posição ativa relativamente à cultura contemporânea. Isso significa atacar aguda e claramente certas posturas ideológico-filosóficas muito caras

e maciçamente acolhidas no meio acadêmico. É parte fundamental dessa estratégia buscar demolir uma certa apresentação de Galileu, mantida, há muito, em que ele é configurado como um herói que luta pela verdade contra as forças do obscurantismo, representadas superlativamente pela Igreja. Em contraposição a esse herói, apresenta-se um outro, este sintonizado com a visão católica, que serve de modelo aos cientistas, católicos ou não, que atua como guia na solução dos complexos e numericamente crescentes pontos de interesse comum entre a ciência e a religião.

Nesse interessante e importante embate cultural, a filosofia anarquista de Feyerabend parece ter alguma função a desempenhar. Uma dessas contribuições que lhe pode caber parece ser a de ajudar a quebrar o monopólio anticatólico da figura e das ideias de Galileu. Afinal, a análise feyerabendiana de Galileu, ao tempo em que o exalta como investigador e teórico, complementarmente mostra-o como um inábil articulador de ideias, que foi mal sucedido em conciliar as inovações teóricas que resultavam de suas investigações com as linhas de pensamento do grande grupo cultural a que pertencia (o mundo cultural católico). Não por acaso, pois, o cardeal Ratzinger/papa Bento xvi escolheu uma citação de Feyerabend sobre Galileu e a Igreja (cf. Ratzinger, 1990), visto que da análise de Feyerabend é possível imaginar uma solução conciliatória entre as ideias de Galileu Galilei e as de Roberto Bellarmino, que parece ser a que idealmente interessa à Igreja e define atualmente a sua linha de ação político-cultural.

Eis, assim, uma das razões do que se assistiu no recente episódio da revolta antipapal de professores e de alunos de La Sapienza. Esses intelectuais fazem parte do grupo dos que estão certos de serem os únicos a poder referir-se à figura de Galileu, de forma que lhes parece que qualquer visão diferente a respeito dessa insigne personagem da história do pensamento não passa de manipulação desavergonhada dos fatos, por parte dos inimigos da ciência, da liberdade acadêmica e da humanidade. 
Há que comentar, para encerrar, algo relativo à repercussão do episódio de $L a$ Sapienza. Não haveria que esperar, não obstante o conflito cultural que está por trás do episódio, nada mais do que algumas notícias na grande imprensa e por breve período, como de fato se deu. Seria todavia de estranhar que não se encontrasse alguma manifestação sobre o caso nos veículos mais representativos da comunidade científica internacional. Com efeito, leem-se em dois números da revista Science, publicados pouco após o conflito, dois textos pequenos vinculados ao assunto, um direta, outro indiretamente. Uma breve nota de Bhattacharjee (2008) descreve o acontecido em La Sapienza, menciona as personagens envolvidas na polêmica (incluindo Feyerabend) e pode ser vista como texto que tem apenas o objetivo de esclarecer um leitor que nada soubesse do assunto, sem outra intenção além de informar; todavia, ao lado do texto, uma ilustração colorida traz um cartaz colado nas paredes da universidade, produzido pelos estudantes antipapistas, em que se lê a frase "O papa é contra a universidade", sobre a qual aparece uma montagem fotográfica, que põe lado a lado Bento xvi e a estátua de Minerva que há na entrada do campus universitário. Pode-se ler a notícia como um simples texto jornalístico ou, como parece mais apropriado, como um editorial subreptício, cujo título foi tomado ao cartaz estudantil. No outro texto (Holden, 2008), lêse que se planeja erigir uma estátua de Galileu, munido de seu telescópio, nos jardins do Vaticano. Explica-se que o objetivo da estátua é dar prosseguimento à revisão do caso Galileu, levada a cabo pelo papa João Paulo Iı, e assim, ao mesmo tempo, homenagear o cientista pelas suas descobertas e pelo papel que desempenha nas relações entre a ciência e a fé. O informante é o físico nuclear Nicola Cabibbo, presidente da Academia Pontifícia de Ciências. Concluída essa informação, aparece no texto (cf. Holden, 2008), subitamente e como contrapeso, a manifestação de descontentamento do astro-físico Simone Recchi, para quem isso não basta, pois a Igreja para contentar os cientistas teria de "concentrar-se em problemas do presente - tais como as células tronco, os contraceptivos, a eutanásia, o aborto - e abrir franco debate [sobre eles]". Que pensar e dizer sobre essa manifestação acre? Certamente que se assistirá por muito tempo ainda a uma encarniçada contenda entre o clássico Galileu anticatólico e o novel Galileu católico.@

Paulo dos Santos Terra Professor Titular do Departamento de Ciências Biológicas, Universidade Estadual de Santa Cruz, Bahia, Brasil. psterra@hotmail.com 


\section{REFERÊNGIAS BIBLIOGRÁFIGAS}

Accatoli, L. Quando o papa pede perdão. São Paulo: Paulinas, 1997.

Artigas, M. Galileo después de la Comisión Pontifícia, 2006. Disponível em: <http://www.unav.es/ cryf/ galileocomision.html\#indice>. Acesso em: 31 jan. 2008.

Bento XVI. Encontro de Bento ХV com os jovens de Roma e do Lácio em preparação para a XXI Jornada Mundial da Juventude. 6 abr. 2006a. Disponível em: <http://www.vatican.va/holy_father/benedict_xvi/ speeches/2006/april/documents/hf_ben-xvi_spe_20060406_xxi-wyd_po.html〉. Acesso em: o1 fev. 2008.

. Encontro com os representantes das ciências. Discurso do Santo Padre. Aula Magna da Universidade de Regensburg. 12 set. 2006b. Disponível em: 〈http:// www.vatican.va/holy_father/benedict_xvi/ speeches/2006/september/documents/hf_ben-xvi_spe_20060912_university-regensburg_po.html>. Acesso em: o1 fev. 2008.

Visita pastoral de Sua Santidade Bento хи a Verona por ocasião do IV Congresso Nacional da Igreja Italiana. Discurso do Santo Padre aos participantes do Congresso. 19 out. 2006c. Disponível em: <http://www. vatican.va/holy_father/benedict_xvi/speeches/2006/october/documents/hf_benxvi_spe_20061019_convegno-verona_po. html>. Acesso em: 01 fev. 2008.

.Encontro do papa Bento XVI com o clero das dioceses de Belluno-Feltre e Treviso. 24 jul. 2007. Disponível em: <http://www.vatican.va/holy_father/benedict_xvi/speeches/2007/july/documents/hf_benxvi_spe_20070724_clero-cadore_po. html>. Acesso em: o f fev. 2008.

. Discurso do Santo Padre Bento XVI para o encontro na Universidade de Roma La Sapienza. 17 jan. 2008. Disponível em: <http://www.vatican.va/holy_father/ benedict_xvi/speeches/2008/january/ documents/hf_benxvi_spe_20080117_la-sa pienza_po.html>. Acesso em: 01 fev. 2008.

Bhattacharjee, Y. (Ed.). On campus. Science, 319, p. 393, 2008. Disponível em: <http:// www.sciencemag. org>. Acesso em: 01 mar. 2008.

Cins, M. La lettera di Marcello Cini. 2007. Disponível em: $<$ http://www.aprileonline. info/5852/la-letteradi-marcello-cini>. Acesso em: o fev. 2008.

Feyerabend, P. Contra o método. Rio de Janeiro: Francisco Alves, 1989.

São Paulo: Unesp, 2007 .

Guimarães, A. The swan's song of Galileo's myth. 2008. Disponível em: <http://www. traditioninaction.org/ History/A_oo3_Galileo.html>. Acesso em: 28 jan. 2008.

Holden, C. (Ed.). Galileo on the Vatican. Science, 319, p. 14,65, 2008.

João Paulo ir. Discurso do Papa João Paulo II à Pontifícia Academia das Ciências por ocasião do primeiro centenário do nascimento de Albert Einstein. 10 nov. 1979. Disponível em: <http://www.vatican.va/holy_ father/john_paul_ii/speeches/1979/november/documents/hf_jp-ii_spe_19791110_eins tein_po. html>. Acesso em: or fev. 2008.

. Discorso di Giovanni Paolo II alla Pontificia Accademia delle Scienze. 3 out. 1981. Disponível em: <http:/ /www.vatican.va/holy_father/john_paul_ii/speeche s/1981/october/documents/hf_jp-ii_spe_ 19811003_accademia-scienze_it.html>. Acesso em: o 1 fev. 2008.

. Discorso di Giovanni Paolo II ai partecipanti alla sessione plenaria della Pontificia Accademia delle Scienze.

31 out. 1992. Disponível em: <http://www.vatican.va/holy_father/john_paul_ii/speeches/1992/october /documents/hf_jp-ii_spe_19921031_accademia-scienze_it.html>. Acesso em: o fev. 2008

Carta encíclica Fides et ratio aos bispos da Igreja Católica sobre as relações entre fé e razão. 14 , set. 1998. Disponível em: 〈http://www. vatican.va/edocs/ PORoo64/_INDEX.HTM〉. Acesso em: o fev. 2008. LetTERA dei 67 fisici della Sapienza, consegnata brevi manu al Rettore Renato Guarini. Roma, 23 nov. 2007. Disponível em: <http://appellolaico. wordpress.com/documenti/>. Acesso em: o fev. 2008. 
A propósito da condenação de Feyerabend em Roma...

Ratzinger, J. Os caminhos da fé no actual momento de viragem. 1990. Disponível em: <http://interregno. blogspot. com/2008/o1/conferencia-do-cardeal-ratzinger-de.ht ml>. Acesso em: 4 fev. 2008.

Theocharis, T. \& Psimopoulos, M. Where science has gone wrong. Nature, 329, p. 595-8, 1987 .

Zenit. Copia e incolla da Wikipedia: 67 docenti per un errore. 6 fev. 2008. Disponível em: <http://www.zenit. org/article-134,13?1=italian>. Acesso em: o 7 fev. 2008.

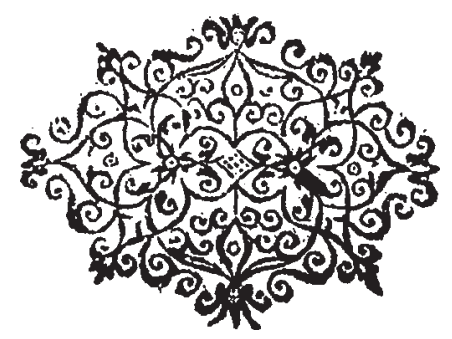

